\title{
POSTPRINT
}

\section{Intersubjectivity and other grounds for action-coordination in an environment of restricted interaction: Coordinating with oncoming traffic when passing an obstacle ${ }^{i s}$}

\author{
Arnulf Deppermann \\ Institut für Deutsche Sprache, PF 101621, 68016 Mannheim, Germany
}

\begin{abstract}
A B S T R A C T
This paper asks whether and in which ways managing coordination tasks in traffic involve the accomplishment of intersubjectivity. Taking instances of coordinating passing an obstacle with oncoming traffic as the empirical case, four different practices were found. 1 . Intersubjectivity can be presupposed by expecting others to stick to the traffic code and other mutually shared expectations. 2. Intersubjective solutions emerge step by step by mutual responsive-anticipatory adaptation of driving decisions. 3. Intersubjectivity can be accomplished by explicit interactive negotiation of passages. 4. Coordination problems can be solved without relying on intersubjectivity by unilateral, responsive-anticipatory adaptation to others' behaviors.
\end{abstract}

Keywords:

Coordination, Traffic, Intersubjectivity, Rule-following, Multimodal interaction, Negotiation

\section{Social order: the issue of the coordination of actions}

While Parsons (1951) considered shared norms and values which are internalized by actors as warrants for social order, ethnomethodology has shown that the constitution of social order is always a situated accomplishment which cannot be predicted nor guaranteed by general rules and norms. Rather, using some very general, formal principles, people create the unique adequacy of their situated actions tailored to the specific contingencies of the emerging local situation (Garfinkel, 1967). From the micro-perspective of the analysis of mundane action, the constitution of social order foremost concerns the issue of how people coordinate their actions as to accomplish a shared reality, e.g. how they organize joint projects of action, get an institutional business done, negotiate individual rights, etc.

\section{Coordination in traffic and the role of intersubjectivity in solving coordination tasks}

Equally adopting an action-based perspective, Goffman (1971) considers traffic as a prime environment for studying the question of how social order is constituted. He takes the flow of pedestrians on a sidewalk as his starting point because it represents a pervasive mundane coordination problem in modern society. The same kind of task has to be dealt with continuously by all kinds of 'vehicular units' (Goffman, 1971, 5-18). Coordination in traffic is required, because there is one scarce resource, namely limited space on the road, which has to be shared. This involves the mutual coordination of movements in order to avoid collisions, taking rights and duties of using the road into account. Goffman highlights the importance of 'scanning' and 'body checks' in order to anticipate others' trajectories and of projecting future actions by 'externalization' and 'body glosses' (Goffman, 1971, 11-12). In a study on crossing a crowded intersection, Liberman (2013, ch.

\footnotetext{
I thank Elwys De Stefani, Henrike Helmer and an anonymous reviewer for valuable comments on a prior version of this paper
}

E-mail address: deppermann@ids-mannheim.de. 
1) identifies practices of coordinating trajectories. While some of them are rather practices of individuals (like searching salient opportunities to pass), others are sequentially organized patterns of intersubjective coordination (e.g. A looks, B recognizes A's looking and A acknowledges B's recognition).

A different approach highlights the role of rules for the solution of coordination problems (Dannefer, 1977; Juhlin, 2010, ch. 4; von Savigny, 1980). Rules can be formal, explicit and codified like the code of traffic, including its priority on safety. Informal rules, like the flow priority, favor actions which contribute to a smooth and efficient management of interdependent trajectories of road-users. Identity-rules include rights and obligations concerning actions in traffic which depend on categorymembership of road-users (e.g. the police, firefighters, car drivers, pedestrians, etc.).

Some of the practices which have been identified in the literature as means to solve coordination tasks in traffic involve intersubjectivity. Intersubjectivity in interaction can be conceptualized in two different ways (Deppermann, 2015a). Both are crucial to our study:

- Intersubjectivity is a presupposition: It is presupposed for the design of every action which is to be understood by others. Intersubjectivity in this original Husserlian sense includes assumptions about sharing a common life-world (Husserl, 1995[1929]) and generic socio-cognitive capacities (Schütz, 1932); it also includes more specific presuppositions about what can be taken to be common ground with the specific partner (Clark, 1996) in the current interactive moment. Intersubjectivity implies trust that other people apply the same rules, maxims and practices of sense-making. Legally, the need to rely on the presupposition of intersubjectivity in traffic is codified in the 'principle of trust' (Vertrauensgrundsatz, StVO Österreich, 2015:§3). It states that people are not required to check whether other traffic participants stick to the traffic code.

- Intersubjectivity is an accomplishment: It is the product of sequentially organized, reciprocal actions, which mutually display and confirm understandings of prior actions (Schegloff, 1992; Sidnell, 2014; Deppermann, 2015b).

Many coordination tasks and ways of solving them are similar to what we find in talk-in-interaction (cf. Sacks et al., 1974; Goodwin, 1981; Auer, 2005). Still, coordination in traffic takes place under aggravated conditions:

- Traffic is risky: Coordination failures result in costly damages and dangerous injuries (von Savigny, 1980).

- Spatial conditions for action change fast, because traffic participants are moving, sometimes at high speed (Haddington, 2013).

- There are multiple possible relevancies for action and different foci of attention which traffic participants may orient to at the same time: There is a heightened chance that a participant fails to monitor relevant events and that mutual awareness will not be established (Nevile and Haddington, 2010).

- There are reduced possibilities for mutual monitoring: Sight is limited (because of windshields reflecting light, people wearing glasses), and there may be long distances between participants and short time frames for mutual monitoring (Haddington and Rauniomaa, 2014).

- Communicative devices to be used for solving coordination problems are constrained: Talk is mostly not available, gestures only if participants are already in relative proximity to each other, technical semiotic aids like flashing lights and horns are highly indexical and therefore prone to misunderstandings, and they are sometimes not sufficient to single out the intended addressee (von Savigny, 1980).

\section{The coordination task: coordinating passing obstacles with oncoming traffic}

This paper studies a recurrent coordination task in traffic involving aggravated conditions. The task we will deal with concerns the issue of who yields right of way to whom (cf. Haddington and Rauniomaa, 2014). It regularly arises if drivers are to pass obstacles like parked cars, road-works, containers, etc. which occupy part of the road making two-way traffic impossible or at least impeded.

Impossibility means that only one traffic participant can pass the obstacle at a time (Fig. 1). In case of oncoming traffic, therefore, one of the participants has to wait before the obstacle and give way to the contraflow. Impediment means that

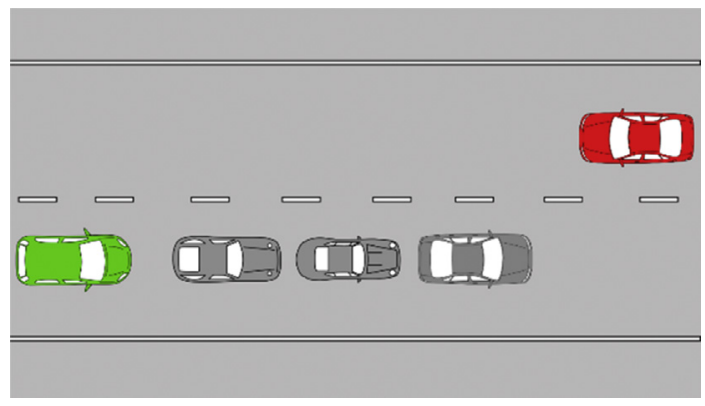

Fig. 1. Giving way to oncoming traffic if simultaneous passing is impossible. 
simultaneous passing is only possible if one participant allows oncoming traffic to use part of their lane - doing so by keeping to the utmost utter margin of their lane.

Paragraph 6 of the German traffic code prescribes the following as solution for this type of coordination problem: 'Whoever wants to pass an obstacle has to give way to oncoming traffic. If it is necessary to veer to the left, one has to monitor the traffic following behind and announce both veering and realignment.' (StVO Deutschland, translation by AD). The traffic code thus provides a basic rule. However, as we will see, the rule is not always applicable, and its situated interpretation is sometimes ambiguous. If it is applicable, the precise details of its situated implementation are still up to local, individual decision or interactive negotiation (cf. Garfinkel, 1967 on rule-following). E.g., if there are obstacles on both lanes and cars are arriving from both sides at the same time, it is not clear who may go first (Fig. 2). The traffic code is also underspecified for situations in which the passer is unable to see in advance that contraflow will be oncoming during the passing procedure (e.g. if it turns around a corner, Fig. 3).

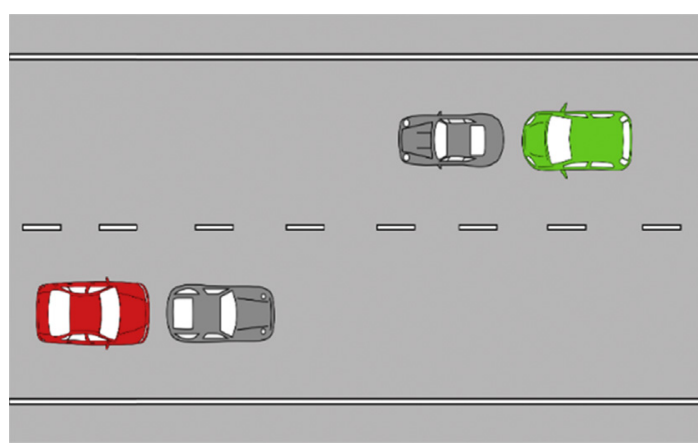

Fig. 2. Obstacles on both lanes.

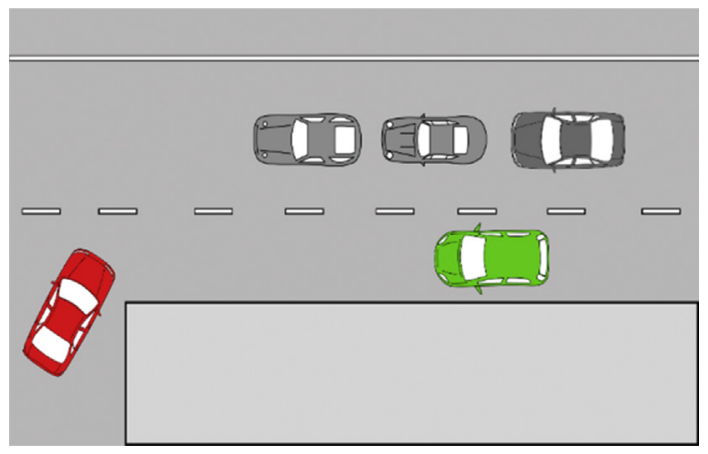

Fig. 3. Contraflow turns up unexpectedly during passing an obstacle.

In the following, we will study how car drivers coordinate their actions when passing obstacles. We will focus on

a. the multimodal resources of the car and the body which are used for solving this coordination problem and the situated traffic conditions of their use,

b. the simultaneous and sequential organization of the actions of the parties to a coordination problem.

Answering these questions will allow us to find out if and when successful coordination is an intersubjective accomplishment. Our analyses will show that intersubjectivity plays an important role in solving coordination problems in traffic. It is presupposed in expecting that other traffic participants follow the code of traffic and more informal rules of conduct. Due to the limited potentials for sign-based interaction, intersubjectivity is only rarely accomplished by interactive negotiation. Instead, implicit intersubjectivity emerges during the process of solving coordination problems by mutual responsive-anticipatory adaptation. However, coordination problems are also solved without relying on intersubjectivity. In these cases, unilateral, responsive-anticipatory adaptation to others' behavior is chosen as a safety strategy. 


\section{The data}

This paper draws on a corpus of $70 \mathrm{~h}$ of recordings of driving school lessons video-taped in Germany in 2012-13 (with two instructors and nine trainee drivers). All lessons were recorded with two cameras (street view and passenger view). For this paper, 17 instances of coordinating rights of way when passing obstacles have been studied in depth. Of course, this kind of coordination task does not only occur in driving lessons. Yet, driving school interactions are a perspicuous setting for the analysis of how participants deal with this task, because learning how to coordinate one's own driving with the actions of other participants is a prime objective of learning. It becomes explicitly topicalized by instructors and is practically dealt with in the lessons, offering situated model solutions to be transferred to future coordination tasks. Since students are not yet fully competent drivers, they often run into problems when dealing with the coordination task. This allows us to identify essential features of managing the task which remain tacit and unnoticed in cases in which coordination is smoothly achieved.

\section{Practices and contingencies of coordinating passing an obstacle with contraflow}

In this section, we analyze three cases of coordinating passing an obstacle with oncoming traffic. For each case, we first track the sequential process of the management of the passage. Since the recordings were made from the perspective of the driving school car, the interaction between the driving school car and the oncoming car as well as the interaction between instructor and trainee driver inside the driving school car will be regarded. Secondly, we highlight the coordination tasks which arise during passing the obstacle. Thirdly, we focus on the practices which are used for solving the task and we discuss if and in which ways they involve the accomplishment of intersubjectivity between road-users. We will show that intersubjectivity figures in solving the coordination task in quite different ways.

\subsection{Rule violations, coordination failures and unilateral, responsive-anticipatory adaptation}

The first excerpt demonstrates the relevance of rules for solving the coordination task by describing a case in which the traffic code is violated. The trainee driver violates the following two rules:

- when approaching an obstacle, he disregards right of way of an oncoming car,

- he fails to announce his intention to pass the obstacle by failing to set the indicator.

The instructor criticizes these violations explicitly and they lead to troubles in coordination. The oncoming car chooses a defensive driving strategy, unilaterally adapting their driving to the rule-violator.

\subsubsection{Sequential trajectory of passing the obstacle}

There are several cars waiting in the lane of the driving school car (DRCR). It will have to pass them as an oncoming car (ONCR) comes into sight. As the trainee driver (TDVR) does not slow down to wait before the next obstacle, the instructor (INST) brakes (using his own brake pedal), grasps the steering wheel, turns it to the right (01-02) and makes the car stop (03).

Excerpt 1a (FOLK_FAHR_01_02; 15:22-15:28)

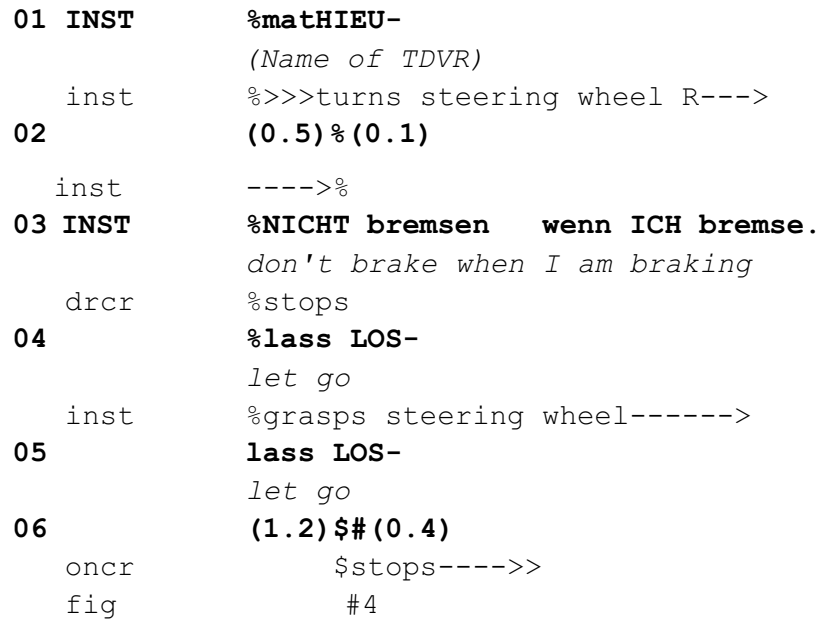


Although the driving school car has stopped (03), ONCR also stops in the distance (about $30 \mathrm{~m}$ away, 06, Fig. 4) and gives way to the driving school car. ONCR does so even though ONCR has no obstacle on its side.

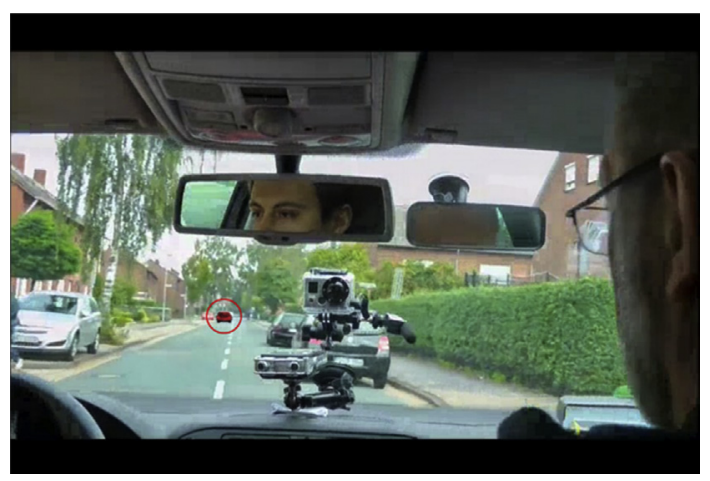

Fig. 4. ONCR stops approx. $30 \mathrm{~m}$ away.

The driving school car is now stopped in its lane before a parked car, without indicating to the left. A backer (BACK) now closes up and starts to veer out behind the driving school car (07-08).

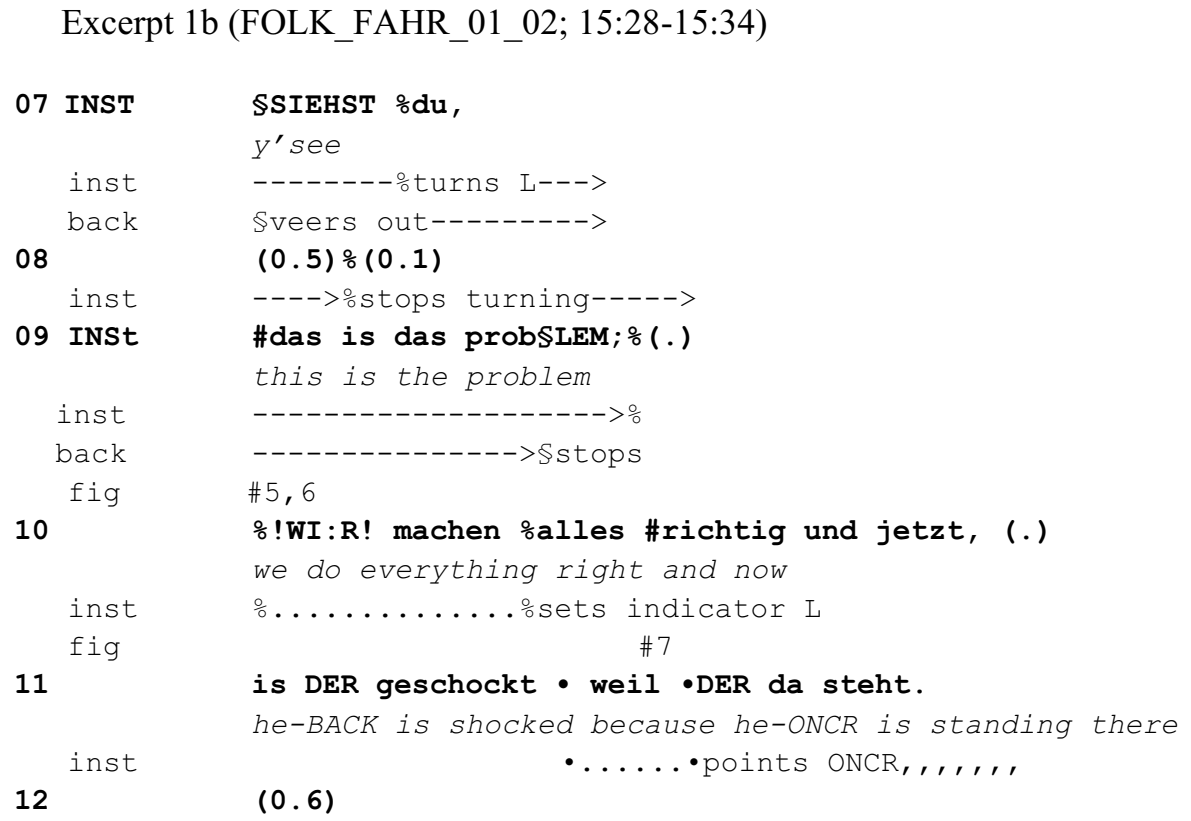

Obviously, the backer mistook the driving school car's waiting in the right lane as parking. However, when veering out in order to pass the driving school car (07-09, Figs. 5-6), the driving school car also moves to the left in order to veer out (07-09).

In addition, the backer probably discovers the oncoming car (which has right of way) waiting in the other lane (see INST' comment in 11; cf. Broth et al., 2019). The backer stops (09). The instructor lets go of the steering wheel and sets the indicator to the left (10, Fig. 7), thus showing that they are not parking but intending to pass the parked car before the backer. After excerpt $1 \mathrm{~b}$, they pass the parked cars. 


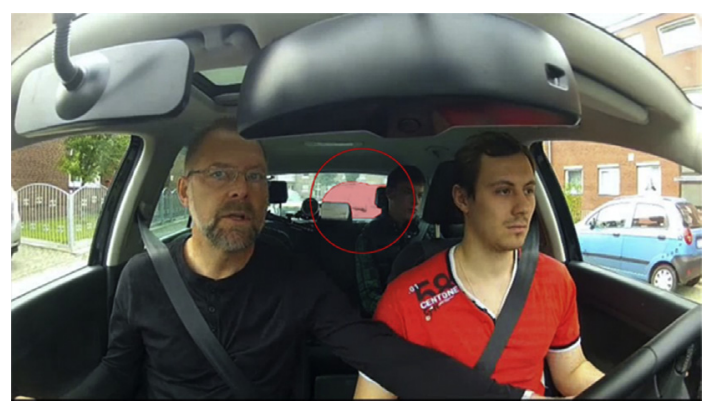

Fig. 5. Backer starts to veer out behind the driving school car.

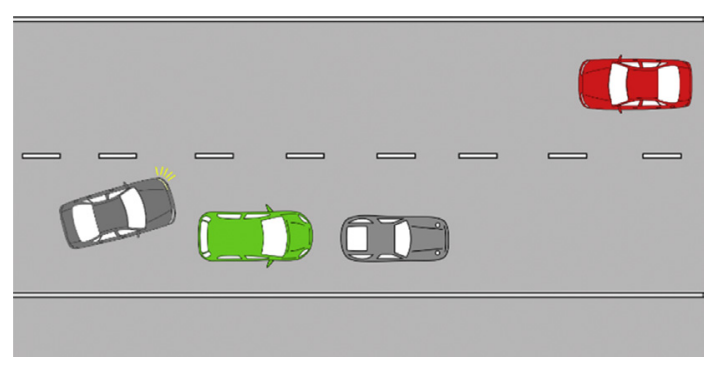

Fig. 6. INST sees it in rear mirror.

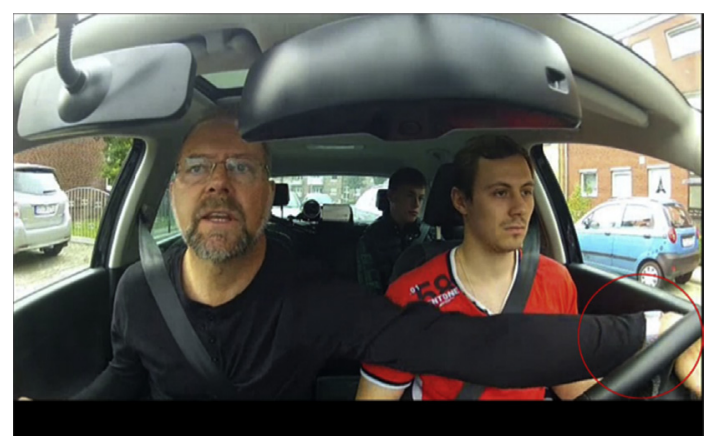

Fig. 7. INST sets indicator to the left.

\subsubsection{Coordination tasks}

The passing of parked cars by the driving school car involves the coordination of actions of three parties: The driving school, oncoming car and the backer. The precise nature of the coordination tasks becomes obvious through the trainee driver's failures to fulfill them properly. They are addressed shortly after they have completed the passage by the instructor:

$$
\text { Excerpt 1c (FOLK_FAHR_01_02; 15:46-15:01) }
$$

25 INST

26
!WIR! haben die hindernisse;

WE have the obstacles

!ER! nicht; (.)

not HIM

un das hättest du da hInten schon SEHN müssen;= and you should have seen this back there already

=un dann hättest !DU! warten müssen;

and then YOU should have waited.

un DESwegen, (.)

and that's why 


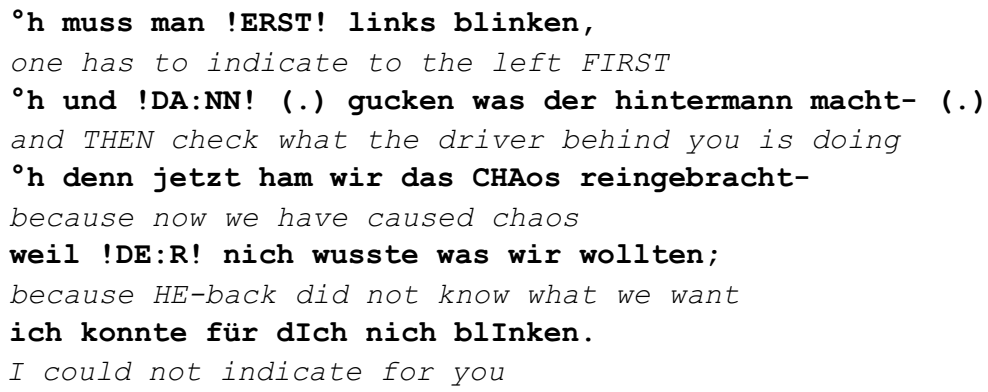

The instructor first criticizes the trainee driver for not having respected the right of way of the oncoming car (25-28), then he reminds him that he must indicate to the left (in order to show that he intends to pass an obstacle, 30) and monitor the backer (31). The instructor attributes the 'chaos' (32), i.e. the fact that the backer erroneously makes a move to pass the driving school car, to the student's failure of not setting the indicator. Both aspects of the German traffic code StVO Deutschland (2013:§6) become relevant here for the driving school car (giving way to oncoming traffic and indicating to the left). The trainee driver violates both of them, which is addressed by the instructor.

The driver who is to pass an obstacle is therefore faced with several coordination tasks:

- Monitoring others: Continuous forward-facing monitoring is required in order to anticipate coordination problems. This includes scanning the road for potential obstacles to be passed and for oncoming traffic, assessing rights and duties of traffic participants, and estimating relevant conditions (relative speed of self and contraflow, distances, size of gaps between obstacles, etc.). Being in a triadic coordination configuration, backward-facing monitoring of the presence and distance of possible backers is equally necessary.

- Projecting own actions: In order to allow others to coordinate their actions with the driver who passes an obstacle, the latter has the communicative task of projecting his driving plans in an intersubjectively observable way (cf. Broth et al., 2018). Taking into account the interdependency of the backer's actions and own actions, in particular, it is necessary to indicate to the left so that the backer can anticipate the driver's actions and adapt theirs accordingly.

- Respecting formal rules: The driver who passes an obstacle has to yield way to oncoming traffic (which has no obstacle on their lane). In order to do so, they have to adapt driving plans and project this in a recognizable way for both oncoming traffic and a potential backer. Projection thus does not only become necessary because of self-initiated plans, but also in response to coordination with third parties and adaptations of own plans (cf. Broth et al., 2018).

\subsubsection{Practices and strategies for solving the coordination task}

The trainee driver fails to manage the task of passing the obstacle because he does not take into account the need to coordinate his driving with other road users behind and further ahead, nor does he make his driving intelligible and anticipatable for them. This leads to wrong conclusions about his driving intentions (parking instead of passing) and to uncoordinated action on the backer's part (attempts to pass the driving school car).

The oncoming car, in contrast, follows a strategy of unilateral, responsive-anticipatory adaptation of its driving. Although having right of way according to the code of traffic, it stops and yields to the driving school car, apparently because the latter is not adhering to traffic regulations. By not slowing down and passing an obstacle while the oncoming car was already in sight, it may seem as though the driving school car was claiming priority of way. Instead of presupposing intersubjectivity of competent members and acting in accordance with the principle of trust, the oncoming car unilaterally adapts its driving in response to the driving school car. It follows a strategy of caution, which avoids harm by acting so that warranting safety is independent from other participants' behavior. In this way, coordination is achieved by driving in a way which does not rely on intersubjectivity, just like one acts to avoid collision with an animal or a tile which might be falling from a rooftop. Suspending the orientation to intersubjectivity includes the suspension of trust in adequate attention, normatively required rule-adherence and rational, considerate driving practices of alter, independence of own driving from semiotic activities of alter and no attempt at negotiating the management of the passage. Still, the unilateral, responsive-anticipatory adaptation is communicative in itself: It is designed to show that the driver gives way. ${ }^{1}$ The cost of this strategy is waiver of right and subordination of own project with respect to the project of alter, which means to lose time.

\footnotetext{
${ }^{1}$ This is understood intersubjectively by the driving school car and by the backer and confirmed by their veering out and going first in passing the obstacle.
} 
Unilateral, responsive-anticipatory adaptation of driving means not to rely on the intersubjectivity of the specific, locally relevant rules of the traffic code, but to orient to a more general maxim instead, which is also stated in the traffic code, namely, the maxim of 'defensive driving' (see StVO Deutschland, 2013: $\$ 1$ : caution and avoidance of dangers are primary objectives when participating in traffic). Defensive driving is in order if a) other road users' adherence to the traffic code cannot be presupposed, b) if traffic conditions are ambiguous, or c) if accomplishment of intersubjectivity is not possible by negotiation (here: because of distance). Most importantly, defensive driving involves renouncing to assert a right conferred by the traffic code in order to avoid danger (see Rechtslexikon).

\subsection{Mutual responsive-anticipatory adaptation: yielding way in an ambiguous situation}

As already mentioned in Section 3, the formal regulations for passing an obstacle in the code of traffic (see above StVO Deutschland, 2013:§6) are insufficient for situations in which both traffic participants are faced with an obstacle on their lane. A defensive strategy in this situation amounts to giving way. If both participants do so, they can adapt their actions to the other party's granting right of way: They can move cautiously forward, reciprocally monitor and reflexively respond to the continuous change in the spatial configuration of the passing procedure until successful completion. This is what happens in excerpt 2.

\subsubsection{Sequential trajectory of passing the obstacle}

The trainee driver notices that a car is turning into their street (01). This noticing already suggests that there will be a coordination problem (cf. Fig. 8) (see Fig. 9).

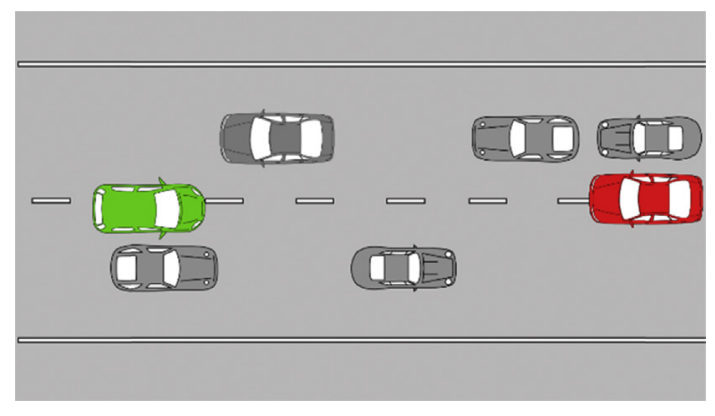

Fig. 8. Coordination task with obstacles on both sides (in excerpt 2).

Excerpt 2 (FAHR_02_21; 56:42-56:54)

01 TDVR was da kommt schon der \#!NÄCHS! te; ${ }^{\circ} \mathrm{hh}$

fig hang on there is already the next one coming

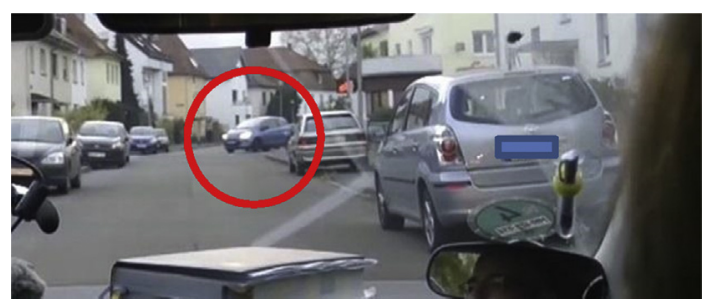

Fig. 9. Another car turns into the street ahead. 


\section{fig \\ 06}

'a'\#

PTCL

tdvr

oncr

drer

fig

\# 10

$+(0.4)+(0.2) \#(0.3)+(0.2) \$(0.2) \#(0.1) \$(0.1) \%$

$+\ldots .+$ raises handt, $, 1,1$, ,

\$raises hand\$

$\# 11$

$\# 12$

opasses ONCR

The oncoming car steers into the nearest gap on its lane (04). Meanwhile the trainee driver slows down and keeps more to the right (04). However, when noticing that the oncoming car moves even further to the right, using the sidewalk of his lane, he steers to the left again, thus initiating the passing of the car ahead of him to the right (04-06).

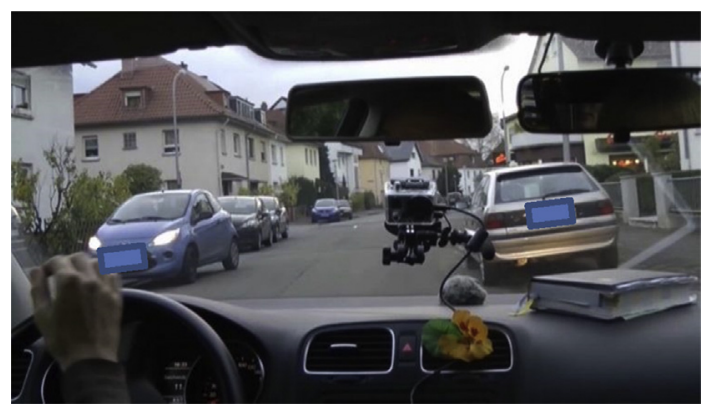

Fig. 10. TDVR initiates passing the parked car to the right, saying ' $\boldsymbol{a}$ '

The oncoming car decreases speed and advances only very slowly, with his right two wheels on the sidewalk (04-06, Fig. 10). The student produces a change-of-state token (05), waves his hand to thank for yielding way (06, Fig. 11), which is reciprocated by the driver of the oncoming car (06, Fig. 12). The student then manages to pass between the oncoming car and the obstacle.

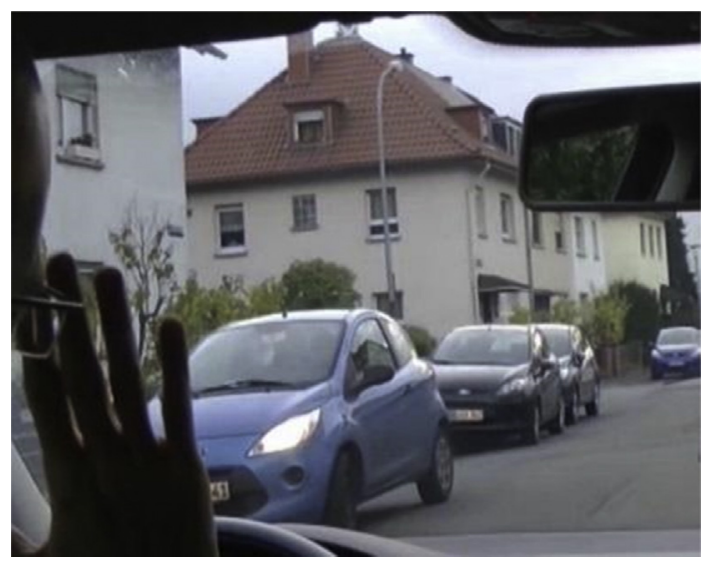

Fig. 11. TDVR waves to thank. 


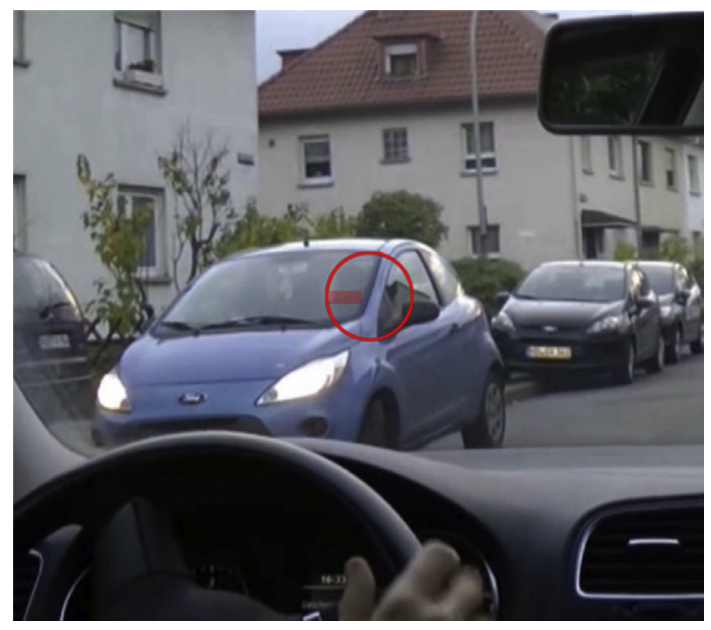

Fig. 12. Driver of ONCR waves to recognize thanks.

\subsubsection{Coordination tasks}

Since the street is crowded with obstacles on both sides, equally interspersed by gaps, there is no unambiguous solution of the coordination task by the code of traffic available. Most importantly it does not determine who has to give way to whom. There are several possible passing places. Opportunities also depend on the speed with which both cars approach each other. These conditions make a number of tasks relevant:

- Monitoring: Drivers have to monitor early for possible oncoming traffic.

- Assessment: They have to continuously assess the distances of obstacles and of the cars vis-à-vis each other, the width of cars in relationship to the available width of street, and the speed of the cars and the possible opportunities ahead to pass.

- Decision: On the basis of continuous monitoring and assessment of the emerging traffic situation, they must decide whether and at which point in the street they will give way to oncoming traffic.

- Projecting own driving: They have to make their decision recognizable to the other driver.

\subsubsection{Practices and strategies for solving the coordination task}

Both drivers follow a strategy of responsive adaptation of driving to the actions of the other party. Initially, by sticking to the right sides of the street, they both drive in a way which may be taken to show readiness for giving way to the other vehicle. Still, the communicative value of such actions is ambiguous. In the first place, driving is movement from one place in space to another. By itself, it is no communicative action. Therefore it is not definitely clear if actions such as slowing down, keeping to the right or stopping are produced to project giving way. In other words, upon their production, it is not entirely clear if the driver produces these actions as communicative actions which are designed to be understood and responded to as such by the other party and, consequently, if the other party can rely on their potential projective potential and build own driving decisions on it. Yet, certain ways of driving in a stylized way index their communicative nature. In such cases, driving is performed in a way which highlights projective properties concerning next actions, often by producing inchoative actions. In excerpt 2, e.g. the oncoming car uses the sidewalk, although passing might as well be possible without doing so. This can be seen as a communicative display of giving way by stylized driving. ${ }^{2}$

Responsive-anticipatory driving is not only a safety strategy; it has also the communicative potential to display that the driver monitors and anticipates others' actions, is ready to adapt their own driving decisions to them and makes own next actions projectable. Over the sequential trajectory of managing a coordination task, a stepwise accomplishment of intersubjectivity can emerge by mutual responsive adaptation and action projection. We see this in excerpt 2: Both drivers advance slowly, each keeping to their right. When the trainee driver realizes that the oncoming car moves to the sidewalk, he treats this as a display to give way. The trainee driver slowly regains the middle of the road, thereby showing that he understood the oncoming car's move as a waiver of rights. The fact that the latter continues to stay partly on the sidewalk without barely moving confirms the trainee driver's understanding as intersubjective. Intersubjectivity is accomplished step-by-step, taking

\footnotetext{
${ }^{2}$ Other stylized driving behaviors include e.g. closing up and moving towards the middle of the road in order to indicate that one intends to overtake the vehicle ahead when the next opportunity arises, and not speeding up when the speed limit increases in order to allow backers to overtake (see Deppermann et al., in print).
} 
the other's actions as possible projective displays, which are cautiously treated as grounds for own actions. The validity of trusting the other is observationally grounded and becomes confirmed by consonant ongoing behavior of the other party. Continuous monitoring, responsive adaption and projection of own next actions are the main components by which this emergent intersubjective coordination is built.

It is important to note that an intersubjective solution here is found without being able to rely on the mechanism of perceived perception (cf. Hausendorf, 2003; see also Goffman, 1971, 13 on 'checked body-checks') and without using semiotic means specialized in communication. It is only in the very last steps of the passage that drivers can definitely perceive that they are in turn being perceived by the other party. Equally, the ambiguity of driving actions as being only potentially communicatively designed and thus having only potentially reliable projective meanings, becomes narrowed down gradually over the emergent collaborative passage.

Only in its final stage, i.e. the passing of the two cars proper, proximal means of interaction which are focused on communication become available, i.e. gestures. The trainee driver's thanking wave (06, Fig. 11) acknowledges the driving actions of the oncoming car as the communicative action of yielding right of way. The reciprocal gesture with two fingers raised of the driver of the oncoming car (06, Fig. 12) in turn ritually acknowledges the thanking gesture (cf. Laurier, 2019). This explicit accomplishment of intersubjectivity about the modalities of the successful management of the coordination task is a ritual post-hoc-confirmation of a collaboratively managed passage, whose intersubjective nature had already gradually emerged before. The explicit semiotic negotiation, however, was not constitutive for the management of the task itself.

\subsection{Interactive negotiation: collaborative management of the passage}

In excerpt 1, the coordination problem was solved by unilateral, responsive-anticipatory adaptation; in excerpt 2, it was an emerging course of implicit reciprocal adaptation and projection during which intersubjectivity was increasingly accomplished. For coordination in traffic, however, there are also semiotic means available which allow for an explicit intersubjective solution of coordination tasks. Indicators, headlight flashes, horns, and stop lights are car controls used for communication (von Savigny, 1980); gestures and sometimes even talk can be used if vehicles are close to each other and drive at slow (or similar) speed (De Stefani and Gazin, 2019).

In excerpt 2, gestures are used to coordinate the passing of several obstacles. As in excerpt 2, the situation in excerpt 3 is ambiguous, because both cars have obstacles in their lanes and there are several possible passing points (Fig. 13).

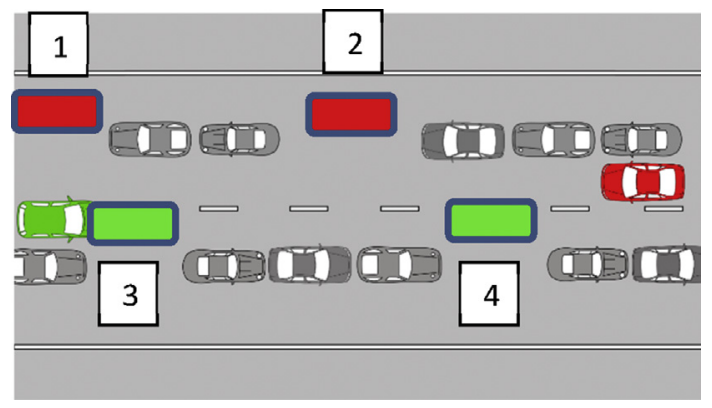

Fig. 13. Coordination task with obstacles on both sides, possible passing points (1, 3, 4) and selected passing point (2).

\subsubsection{Sequential trajectory of passing the obstacle}

The trainee driver expresses his noticing of the oncoming car by asking the instructor how the coordination problem can be solved (01). On the side of the driving school car there is a long array of parked cars (Fig. 14). There is only a small gap (between the red and the blue car on the right of the street), which the trainee driver could use for stopping and letting the oncoming car pass, however, with difficulties. The trainee driver does not use this opportunity (and is not criticized by the instructor for this).

Excerpt 3a (FAHR_02_21; 1:06:52-1:07:20)

01 TDVR

oncr

fig <<creaky> ah> \$SO,\# (.) was mach mer JETz- (.)

oh so and what do we do now?

\$comes into sight

\# 14 


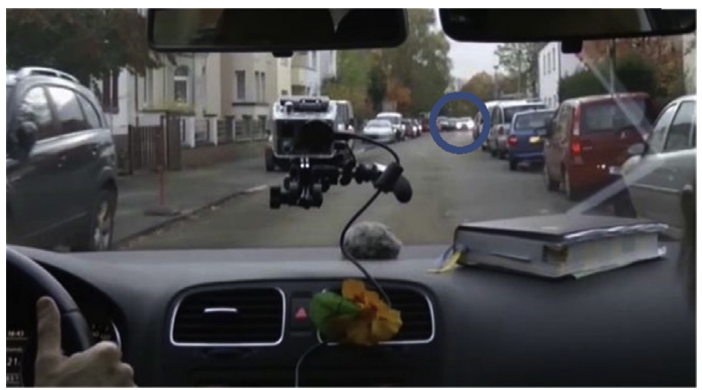

Fig. 14. Oncoming car comes into sight.

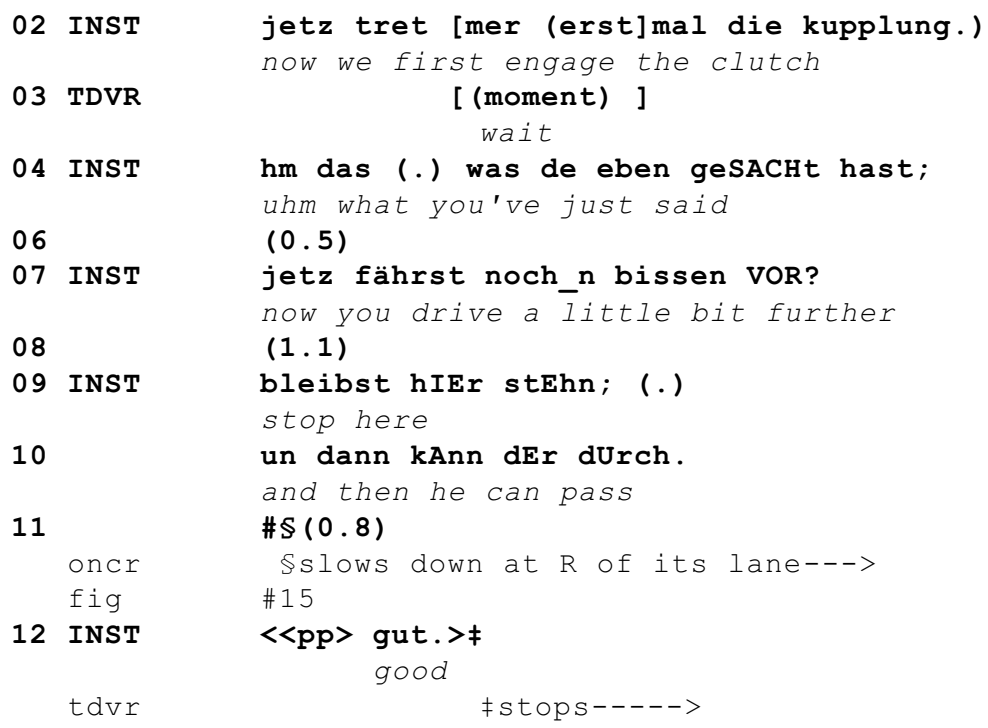

As can be seen in Fig. 14, there is a large gap on the left side (gap 1 in Fig. 13), which is suitable for passing. Yet, when the trainee driver notices the oncoming car, he is much closer to this possible passing space than the oncoming car. His question 'ah so was mach mer jetzt' ('oh so what do we do now', 01) treats it as a non-routine, problematic situation. The instructor gives precise instructions how to approach the passing space (02-10, gap 2 in Fig. 13): the student is to engage the clutch (02) and to stop (09) so that the oncoming car can pass (10). The driving school car finally comes to a halt in 12 . At the same time, the oncoming car orients increasingly to the right of its lane and slows down as well (Fig. 15).

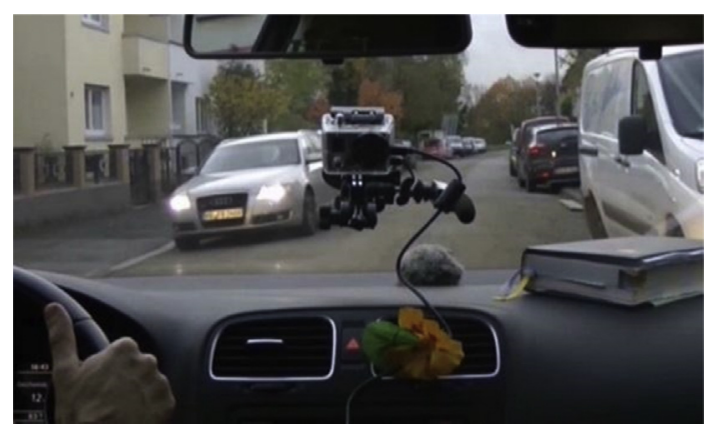

Fig. 15. Oncoming car slows down. 
In order to pass, the oncoming car keeps to its utmost right, but, in contrast to excerpt 2, it does not use the sidewalk. The passing space is still very narrow and requires delicate navigation. The trainee driver now enters into a negotiation of the passing procedure with the driver of the oncoming car.

\section{Excerpt 3b (FAHR_02_21; 1:06:52-1:07:20)}

13

14 INST

tdvr

oncr

fig

15

oncr

fig

(0.5)

Ertster\# g\$Ang, +

first gear

+point $\mathrm{L}-----+$

$--------->$ \$stops------->

\#16

$(0.4) \$(0.4) \#$

\$waves hand--->

\#17

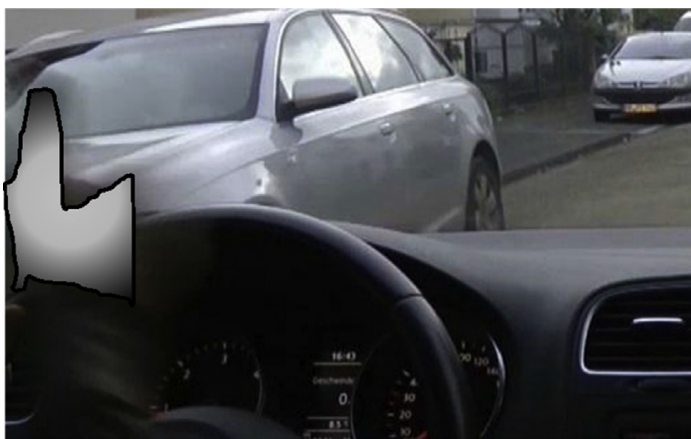

Fig. 16. Trainee driver points left.

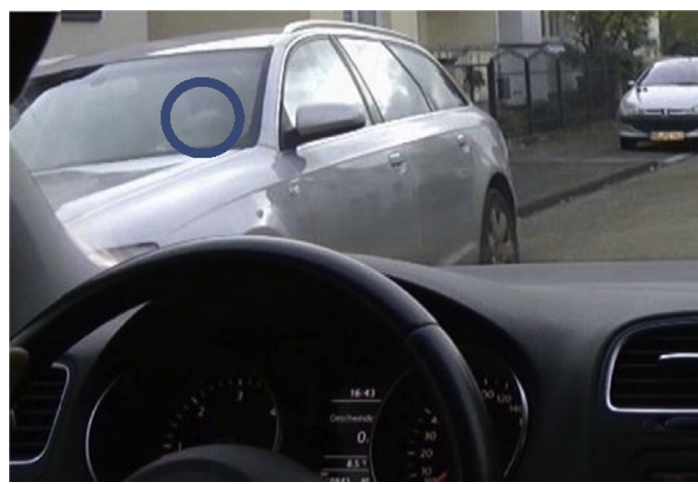

Fig. 17. Driver of oncoming car waves hand.

nh*a \$es wird en bissel +\$KNAPP;+

well it's getting a bit tight

inst

..*looks L,

+point L+

oncr

$---->\$$

oncr 
The negotiation starts with the trainee driver pointing to his left (13, Fig. 16), indexing that the oncoming car should move even more to its right. At this moment, the oncoming car has stopped immediately before the driving school car. The driver of the oncoming car acknowledges the point by a hand wave (15-16, Fig. 17), thus seeming to project that they will comply with the request made by the trainee driver's point. Monitoring the lateral space of the road to the left of their car (16), the instructor remarks that it is rather narrow for passing (which can be seen as a support for the student's request by pointing). Simultaneously with the student renewing his request by a second point (16), the oncoming car moves slowly further right (16). Now there is sufficient space for the passage to be accomplished. Still, there is some work left to coordinate the trajectories of the two cars in their respective directions.

The instructor now asks the trainee driver to 'drive a little bit with (the other car)' (18), i.e. to move the car forward again. The oncoming car has stopped in the meantime in a gap on its right (18, gap 2 in Fig. 13). The driving school car must now advance in order to allow the oncoming car to leave its gap and to resume its trajectory.

Excerpt 3c (FAHR_02_21; 1:06:52-1:07:20)

17 TDVR

18 INST

inst

oncr

19

20

21

tdvr

22 INST

fig

23 TDVR

\section{(( (schnaubt lachend)) okAY,}

((snorts while laughing)) okay

ja musst jetz n_•bissel •MIT\$fahrn;

yes you now have to drive a little bit with (him)

$$
\text { -.......point fwd, , , , }
$$

GUCK mal;

look

jetz hAste ja noch genuch plAtz.

now you still have enough space

$(2.0) \neq(0.4)$

$->\neq d r i v e s$ on-------------->>

\#guck [nach vorne, ]

look ahead

$\# 18$
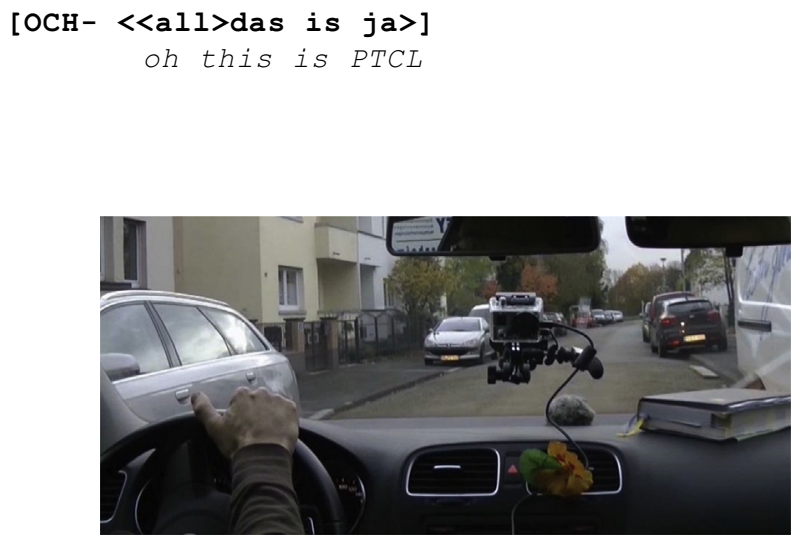

Fig. 18. Trainee driver sets car again into motion to pass.

24 INST

25 TDVR

oncr

guck nach [VoRne; ]

look ahead

[dem KAR]le reicht \$das;

for Name-TDRV it is enough

$->$ \$drives on------->>

vielleicht bekommt man nicht den SPIEgel abrasiert.>

maybe we won't have the mirror knocked off 
As the trainee driver does not immediately comply with the request to move on (cf. 18), the instructor reassures him that there is enough space to pass (20). The trainee driver sets the car in motion again (21, Fig. 18), confirms that there is sufficient space to move on (25) and comments ironically on the fact that there will be no damage, in spite of the narrowness of the passage (26). Finally, the oncoming car also resumes its trajectory (25).

\subsubsection{Coordination tasks}

There is no unambiguous solution for the coordination task: the traffic code (StVO Deutschland $\S 6$ ) does not apply or provides no guidance for the situation where both drivers have obstacles in their lane. There are several possible passing points when the oncoming car comes into sight (Fig. 19 = Fig. 13):

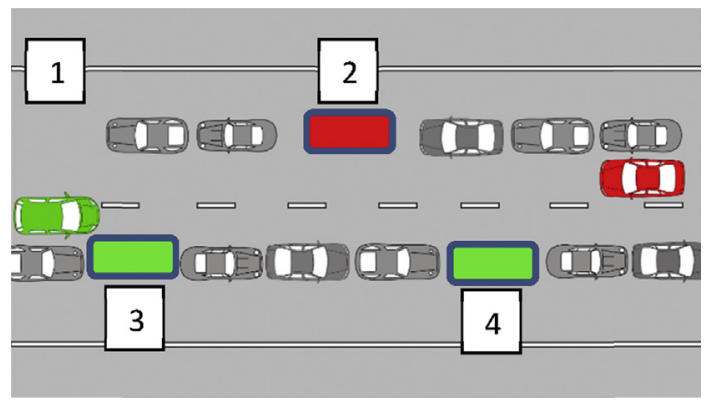

Fig. 19. Coordination task with obstacles on both sides, possible passing points $(1,3,4)$ and selected passing point (2).

- The trainee driver could stop immediately (gaps 1 and 3 in Fig. 19) - this would require abrupt braking and could be dangerous;

- He could speed up and stop at gap 4 in Fig. 19 - speeding up could be understood as claiming right of way in an aggressive and dangerous way;

- The passing point which was eventually chosen required from the oncoming car to use gap 2 in Fig. 19. This is the mutually preferred coordination point regarding both mutual visibility and speed. It allows for relatively smooth and safe driving for both parties.

However, convening on the passing point is not enough. There was an additional need to fine-tune the passing procedure in terms of coordinating the management of lateral space, of driving slowly and of stopping.

\subsubsection{Practices and strategies for solving the coordination task}

Since rules are insufficient for coordinating the passage, here agreement on the passing space is in part achieved by means of reciprocal expectations of expectations built on rational reasoning concerning suitable spatial configurations and driving opportunities. This way of solving a coordination problem bears resemblance to a Schelling game (Schelling, 1960:54-58). The passing space on which both parties convene as being most suitable is a focal point for each person's expectation of what the other expects him to expect to be expected to do' (Schelling, 1960:57). The salience of the focal point in the task of coordinating passing obstacles is defined by the places of obstacles, the width of the moving and the parked cars and the (remaining) road, and their (relative) speed and distances to each other.

The shared definition of the focal point, however, is not fully double-blind, non-interactive in traffic as in a real Schelling game. Drivers monitor continuously if the other driver can be understood to head for the same focal point; if not, they adjust their driving emergently. So, while coordination in traffic may start as a Schelling game, it increasingly becomes transformed and (dis-)confirmed by ongoing (projective) displays and realizations of the projected trajectory (which may be intersubjectively shared and oriented to). In excerpt 3, e.g., the decrease of speed by the driving school car indexes that it waits for the oncoming car to reach the focal point, i.e., a passing space in proximity of the driving school car.

While the drivers converge on the same focal point, they still have to manage the space for passing through local negotiation. By using gestures they produce more or less unambiguous communicative actions which index driving plans and giving right of way. Gestural negotiation of priority (for the driving school car) and direction (the move of the oncoming car to its right) are accomplished in a three-part-sequence:

(1) The trainee driver points to his left, i.e. to the right of the oncoming car (14);

(2) The confirming gesture of the driver of the oncoming car projects compliance (15-16);

(3) The oncoming car moves to its right (16).

In addition, the pass is accomplished by reciprocal responsive-anticipatory adaptation of speed in terms of advancing slowly and stopping in reaction to the other's actions and to the changing spatial conditions of the road (see Table 1 ). 
Table 1

Reciprocal adaptation of speed of driving school car and oncoming car.

\begin{tabular}{lll}
\hline & Driving school car & Oncoming car \\
\hline Approaching the passing space & Drives slowly (01-12) & Drives slowly (11-14) \\
Coordinating in the passing space & Stops (12-21) & Stops (14-16) \\
& & Drives slowly (16-18) \\
& & Stops (18-25) \\
Leaving the passing space & Drives on (21ff.) & Drives on (25ff.) \\
\hline
\end{tabular}

The trainee driver's adaptive management of speed is guided by the instructor who requests and accounts for the relevant situated changes in the student's actions. In excerpt 3, a great variety of resources and strategies is used for the solution of the coordination problem. Monitoring, reasoning (Schelling game) and slowing down (which counts both as a physical and a communicative action) are used at a distance. Gestures and mutually perceived gaze can only be used under conditions of proximity (reciprocal visibility of drivers, cf. Haddington and Rauniomaa, 2014) and low speed.

\section{Summary and discussion}

This paper has dealt with coordination tasks in traffic and the resources and strategies by which they are collaboratively solved. The focus was on the task of passing obstacles in two-way traffic, which involves coordinating right of way and the point of passing. The aim was to provide a microsociological and multimodal analysis of coordination and intersubjectivity in traffic. Passing obstacles is a particularly interesting object for the study in this respect. For solving this kind of coordination task, traffic regulations are often insufficient and in need of being supplemented or even overruled by more general maxims of cautious and rational conduct on the one hand, and by decisions built on responsive-anticipatory adaptation and interactive negotiation. Interestingly, this general view of coordination in traffic is codified in the German code of traffic in a similar way. In addition to paragraphs which apply to specific traffic situations (such as StVO Deutschland, 2013:§6), it includes general maxims stated in $\S 1$ (caution, respect) and the need for interactive negotiation in situations which can neither be mastered by rules nor by maxims alone (StVO Deutschland, 2013:§11,2).

Managing the coordination task is a situated accomplishment, involving a number of monitoring and decision tasks. It requires driving in a prudent, far-forward looking manner, which involves anticipating coordination tasks and assessing them with respect to several parameters:

- distance to oncoming traffic,

- width of the road and the vehicles,

- positions of obstacles,

- possible spaces for passing,

- own speed and speed of oncoming traffic, relative speed.

As a consequence, there are a couple questions that drivers have to answer in order to make driving decisions:

- When will the parties probably reach a possible point of passing? Who is first, given the current speed of both participants?

- May ego pass first, if ego speeds up?

- Is there a rule about who has priority?

- Does ego have to slow down in order to let alter pass first?

- Does alter project to give way (by slowing down, waving, flashing headlights)?

- If ego gives way to alter: where to stop?

These parameters cannot be assessed and planned once for all. They must be updated continuously in the emergent process of coordinating the passages.

Coordination in traffic can involve intersubjectivity, but it need not do so. In this paper, we have identified four strategies of coordination in which intersubjectivity plays different roles.

- Presupposition of intersubjectivity

Drivers can expect that other road users adhere to mutually known (traffic) rules. This may work in unambiguous situations where the applicability of the code of traffic is obvious. It is a resource to reduce complexity in solving coordination tasks and an institutionalized functional substitute for negotiation. The rules of the code of traffic take into account the specific contingencies of coordination in traffic. Reduced possibilities for communication (restricted mutual perceptibility and semiotic resources, ambiguity of resources, no metacommunication, restricted possibilities for negotiation) and increased risk (damages) create the need for the development of stable, reliable, unambiguous, commonly known, widely usable and obligatory practices. They provide model solutions for recurrent coordination tasks. They can be administered 
locally, without knowing others' intentions, independently of negotiation and ratification. They are substitutes for perceived perception and semiotic displays (although, of course, demanding certain displays in certain situations). Their application mainly requires the observation of traffic conditions and their change.

In more anomic and ambiguous situations, Schelling games, i.e. the reliance on shared reasoning strategies which reflexively take the others' perspectives into account, are needed to manage coordination tasks. Both rule-following and shared reasoning rest on mutual trust: They presuppose that all road-users stick to the code of traffic, that their actions are rationally and morally accountable in terms of attention, caution, categorizing situations and assessments of possibilities for actions, rights and duties. All semiotic practices for solving coordination tasks (like setting the indicator, performative driving, etc.) require trust in expectations (of expectations) of interpretations, in mutual perception and in the situated recognition of requirements on own driving which arise from others' driving. Intersubjectivity thus implies trust in adherence both to shared specific rules and to flexible maxims, which are implemented given the situational contingencies in an accountable way. If traffic participants did not presuppose the principle of trust regularly, traffic would break down. If participants acted so as to avoid any dangerous situation which could arise because of any possible violation of the traffic code by others, quick, smooth and efficient traffic flow would be impossible.

- Emerging implicit intersubjectivity by mutual responsive-anticipatory adaptation

The successful management of a coordination problem successively accomplishes intersubjectivity. Successful management implies that the validity of assumptions about others' rational and normative understandings of what their driving behavior should project are fulfilled. In this way, an initial presupposition of an intersubjective orientation to a coordination problem (see above) is increasingly validated by a series of coordinated, expectation- and projection-fulfilling actions. Accomplishment of intersubjectivity in this way is not a one-shot event. It extends over the whole trajectory of the management of the coordination problem. In each moment of its trajectory, intersubjectivity is a fragile state. It is in need of continuous performative confirmation, often adopting the shape of gradually increasing certainty about the predictability and trustworthiness of others' behavior. Accomplishing intersubjectivity in this way does not necessarily rely on meta-coordinative, specialized accounts. Rather, it is the successful match of interlocking actions and of expectations and actions which can be taken as evidence for intersubjectivity.

- Intersubjectivity by interactive negotiation:

In contrast to emergent intersubjective coordination, interactive negotiation requires actions which are specifically designed to make driving intelligible, to request and to project actions by specialized semiotic means, to confirm, account for, and thank for actions. Negotiation requires activities which are perceivable as unambiguous communicative actions in their local context. Yet, it is difficult to judge if driving actions are also communicative actions, designed to be understood for their projective, confirming, granting, etc. values. In contrast to talk, driving actions are not specialized in communication. As such, they are movements, whose primary rationale is to transport persons or goods. Driving activities may be motivated by various reasons and causes; e.g. slowing down may be done in order to park, to look for something, to do other things than driving (e.g. check the smart phone), out of fear of oncoming traffic, etc. Driving thus can, but does not necessarily communicate what the driver intends to do next or what they expect other traffic participants to do. Moreover, if traffic participants are far apart, it is not sure whether there is mutual perception - and even more so concerning drivers' expressive means. For these reasons and because of their own physical properties, the usability of semiotic means in traffic is rather limited. If participants are far apart, bodily interaction between road users by gestures, head nods and gaze contact is impossible. Other participants' gaze can only be monitored when being very close. There are some resources of the car which are specialized for communicative purposes and which may be used for distant communication: indicating, headlight flashing, hazard flashes, intermittent braking (and thus communication by stop lights) and beeping. However, these resources are all highly indexical and ambiguous (von Savigny, 1980), even up to the point that it is not clear who is concerned (e.g. when beeping). ${ }^{3}$ The most unambiguous device, indicating, is restricted to signal left-right movements. For these reasons, interactive negotiation mostly can only play a role for solving coordination tasks in the later phases of the process, when drivers can monitor each others' bodies.

- Unilateral, responsive-anticipatory adaptation:

Solving a coordination problem does not necessarily involve intersubjectivity. Unilateral, responsive-anticipatory adaptation is the strategy needed if trust in the intersubjective management of a coordination task does not seem to be warranted. Other participants' behavior may suggest that a) they do not stick to rules (e.g. they drive by excessive speed), b) they do not perceive ego (e.g. they do not seem to adapt their actions to own actions) or c) they cannot be interpreted unambiguously (e.g. driving slowly without an intelligible reason). Equally, their category membership (like children, animals, blind people) can index that there is no common ground of stable mutual behavioral expectations and they are not capable to follow the code of traffic. If the principle of trust is suspended, participants unilaterally adapt their driving to the projectable 'worst-case' behavior of others. Unilateral, responsive-anticipatory adaptation is a strategy of caution. It avoids harm by acting in a way that safety is secured independently from other participants' behavior. The driver contributes to solving the coordination task so that it can be managed successfully without having to rely on presupposed or achieved or negotiated intersubjectivity. Suspending the orientation to intersubjectivity

\footnotetext{
${ }^{3}$ Headlight flashing may mean, e.g. 'I give way to you'; 'yield right of way'; 'speed up'; 'attention: speed/police control ahead'; 'attention: accident ahead'; 'your car has a problem'; 'you are not driving correctly'; 'thank you' etc. (cf. von Savigny, 1980).
} 
includes the waiver of rights and the suspension of trust in attention, rule-adherence and rational, considerate driving practices of alter. It involves renouncing negotiation and basing one's own driving on semiotic activities of others. While this strategy means to act independently from relying on an intersubjective orientation of others, it is itself communicatively designed, projecting that right of way is ceded. Still, it is often not clear from an observer's point of view whether responsive-anticipatory driving is only motivated by physical caution or if it is intended as communicative action.

Coordination tasks in traffic are neither sufficiently managed by abstract rules nor by interactive negotiation. They require continuous situated monitoring in order to anticipate others' actions and to make own adaptive driving decisions which build on these anticipations. This precisely seems to be the primary raison d'etre of driving lessons: To be exposed to situations that are not pre-defined and are not sufficiently governed by the code of traffic, and to learn situated solutions by taking the everchanging local circumstances into account. Communication and intersubjectivity play a crucial but fragile role in this process: The communicative value of actions is often ambiguous and the validity of the presupposition of intersubjectivity is not settled. Both can only be worked out reflexively over the course of accomplishing a coordination task.

\section{Appendix. Transcription conventions}

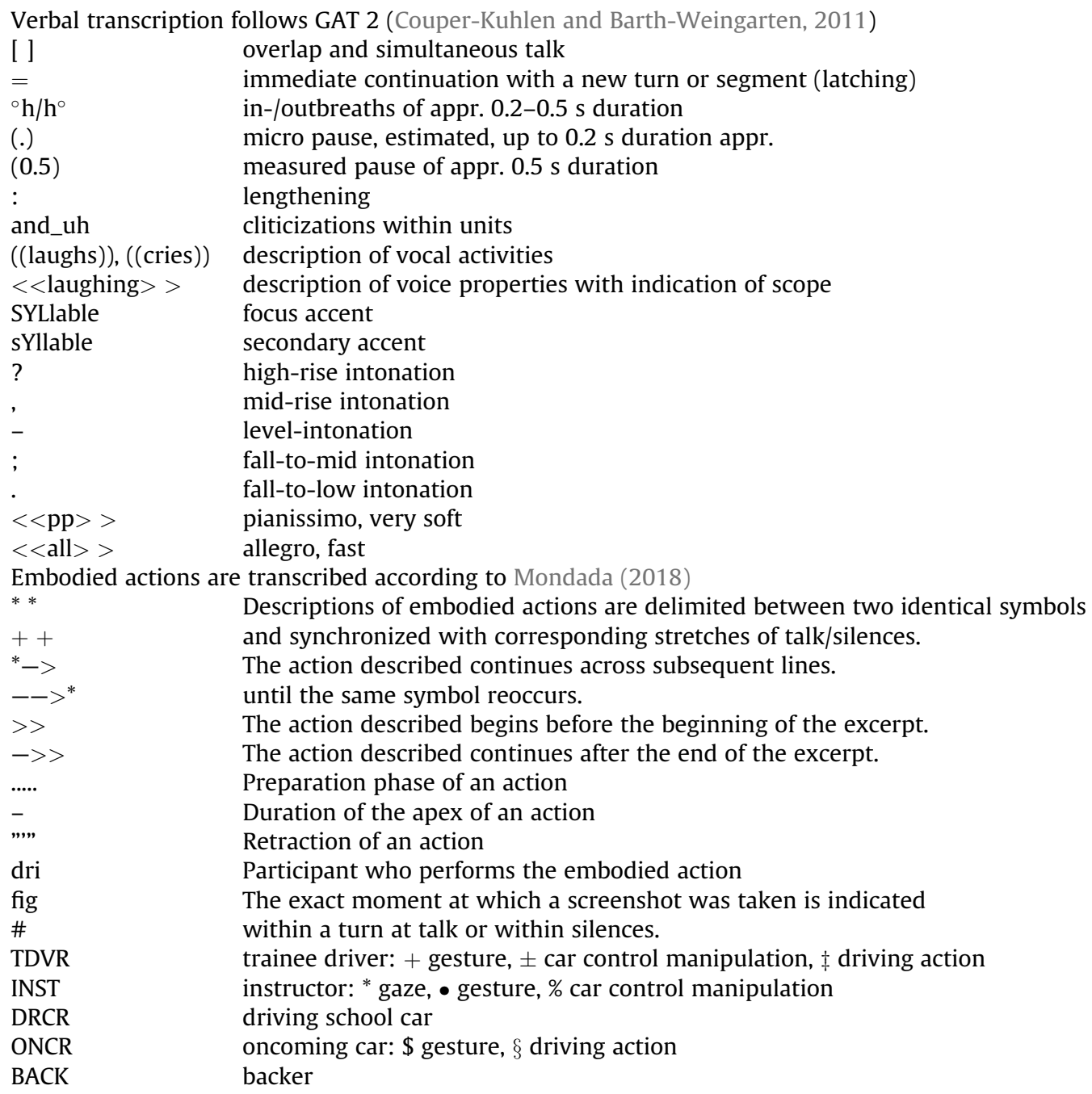

\section{References}

Auer, P., 2005. Projection in interaction and projection in grammar. text 25 (1), 7-36.

Broth, M., Cromdal, J., Levin, L., 2018. Showing where you're going. Instructing the accountable use of the indicator in live traffic. Int. J. Appl. Ling. https://doi. org/10.1111/ijal.12194.

Broth, M., Cromdal, J., Levin, L., 2019. Telling the Other's side. Formulating others' mental states in driver training. Lang. Commun. 65, 7-21. 
Clark, H., 1996. Communities, commonalities, and communication. In: Gumperz, J., Levinson, S. (Eds.), Rethinking Linguistic Relativity. CUP, Cambridge, pp. $324-355$.

Couper-Kuhlen, E., Barth-Weingarten, D., 2011. A system for transcribing talk-in-interaction: GAT 2. Gesprächsforschung/Discourse and Conversation Analysis 12, pp. 1-51. www.gespraechsforschung-online.de/fileadmin/dateien/heft2011/px-gat2-englisch.pdf.

Dannefer, W.D., 1977. Driving and symbolic interaction. socio. inq. 47 (1), 33-38.

De Stefani, E., Gazin, A.-D., 2019. Learning to communicate: managing multiple strands of participation in driving lessons. Lang. Commun. 65, 41-57.

Deppermann, A., 2015a. When recipient design fails: egocentric turn-design of instructions in driving school lessons leading to breakdowns of intersubjectivity. In: Gesprächsforschung/Discourse and Conversation Analysis, vol. 16, pp. 63-101. http://www.gespraechsforschung-ozs.de/dateien/heft2015/ ga-deppermann.pdf.

Deppermann, A., 2015b. Retrospection and understanding in interaction. In: Deppermann, A., Günthner, S. (Eds.), Temporality in Interaction. Benjamins, Amsterdam, pp. 57-94.

Deppermann, A., Laurier, E., Mondada, L., et al., 2018. Overtaking as an accomplishment in live traffic. In: Gesprächsforschung/ Discourse and Conversation Analysis, vol. 18 (in print).

Garfinkel, H., 1967. Studies in Ethnomethodology. Prentice-Hall, New York.

Goffman, E., 1971. Relations in Public. Basic Books, New York.

Goodwin, C., 1981. Conversational Organization. Academic, New York.

Haddington, P., 2013. Action and space: navigation as a social and spatial task. In: Auer, P., Hilpert, M., Stukenbrock, A., Szmrecsanyi, B. (Eds.), Linguistic Perspectives on Space: Geography, Interaction, and Cognition. Gruyter, Berlin, pp. 411-433.

Haddington, P., Rauniomaa, M., 2014. Interaction between road users: offering space in traffic. space cult. 17 (2), $176-190$.

Hausendorf, H., 2003. Deixis and speech situation revisited. The mechanism of perceived perceptions. In: Lenz, F. (Ed.), Deictic Conceptualisation of Space, Time and Person. Benjamins, Amsterdam, pp. 249-269.

Husserl, E., 1995[1929]. Cartesianische Meditationen. Meiner, Hamburg.

Juhlin, O., 2010. Social Media on the Road. Springer, London.

Laurier, E., 2019. Civility and mobility: drivers (and passengers) appreciating the actions of other drivers. Lang. Commun. 65, 79-91.

Liberman, K., 2013. More Studies in Ethnomethodology. SUNY Press, Albany, NY.

Mondada, Lorenza, 2018. Multiple temporalities of language and body in interaction: challenges for transcribing multimodality. Res. Lang. Soc. Interact. 51 (1), 85-106.

Nevile, M., Haddington, P., 2010. In-car Distractions and Their Impact on Driving Activities. Department of Transport and Infrastructure, Australian Commonwealth Government, Canberra.

Parsons, T., 1951. The Social System. Routledge and Kegan Paul, London.

Rechtslexikon http://www.rechtslexikon.net/d/defensives-fahren/defensives-fahren.htm.

Sacks, H., Schegloff, E.A., Jefferson, G., 1974. A simplest systematics for the organisation of turn-taking for conversation. language 50, 696-735.

Schegloff, E.A., 1992. Repair after next turn: the last structurally provided defense of intersubjectivity in conversation. Am. J. Sociol. 97 (5), $1295-1345$.

Schelling, T., 1960. The Strategy of Conflict. Harvard UP, Cambridge, MA.

Schütz, A., 1932. Der sinnhafte Aufbau der sozialen Welt. Springer, Wien.

Sidnell, J., 2014. The architecture of intersubjectivity revisited. In: Enfield, N.J., Kockelman, P., Sidnell, J. (Eds.), Cambridge Handbook of Linguistic Anthropology. CUP, Cambridge, pp. 364-399.

StVO Deutschland, 2013. Straßenverkehrsordnung. 12. Aufl. Beck, München.

StVO Österreich, 2015. Straßenverkehrsordnung. 14. Aufl. Manz, Wien.

Von Savigny, E., 1980. Die Signalsprache der Autofahrer. dtv, München. 